\title{
Case Report of Autoimmune Haemolysis with Lymphoma-Managing the Impossible
}

\author{
Gunawardena D*, Moonesinghe CS, Wijesiriwardena IS and Kulathilake HWCK
}

Department of Pathology, Faculty of Medical Sciences, University of Sri Jayewardenepura, India

\begin{abstract}
Non-Hodgkin's lymphoma can be associated with an autoimmune haemolytic anaemia causing recurrent episodes of haemolysis, giving rise to problems in a slowly progressive low grade lymphoma. Managing such a patient can be a challenge. We report such a patient who refuses transfusion of blood products for religious reasons, which makes the challenge even more impossible to manage. This case highlights how this situation was managed successfully with available, less aggressive therapy.
\end{abstract}

Keywords: Autoimmune haemolytic anaemia; Non-Hodgkin's Lymphoma

\section{Case Report}

A 65 year old lady presented with vague ill-health, dyspnoea and feeling unwell for 1 month duration. She was anaemic, with massive splenomegaly of $6 \mathrm{~cm}$ below the left intercostal margin. She had no lymphadenopathy, icterus or any other signs. Her investigations revealed haemoglobin of $5.5 \mathrm{~g} / \mathrm{dL}$, WBC- $9,000 / \mathrm{mm}^{3}$ with normal differential count and a platelet count of $102 \times 103 / \mathrm{mm}^{3}$. Blood picture showed occasional spherocytes, few reticulocytes with no abnormal cells. Reticulocyte count was $14 \%$. Direct antibody test (DAT) was positive and DAT profile showed IgG+C3d positivity which confirmed a warm autoimmune haemolytic anaemia [1]. Bone marrow showed moderate infiltration of lymphoid cells with erythroid hyperplasia. Rest of the haemopoietic elements was normal. Immunohistochemistry of the trephine revealed the lymphoid cells to be CD 20 positive and CD 10 negative. A diagnosis of Non-Hodgkin lymphoma (probably splenic marginal zone) was made with a secondary warm autoimmune haemolytic process. Although she was symptomatic, red cell transfusions were not possible due to her religious constrains. She was started on prednisolone $1 \mathrm{mg} / \mathrm{kg} /$ day and within 2 weeks of treatment her haemoglobin recovered to $9 \mathrm{~g} / \mathrm{dL}$. Steroids were gradually tailed off; however, DAT continued to be positive. She was clinically stable and maintained normal haemoglobin for 3 yrs. Following that she had a severe bout of haemolysis with $\mathrm{Hb}-5.3 \mathrm{~g} / \mathrm{dL}$ with a reticulocyte count of $17 \%$. Different therapeutic options were tried such as Methylprednisolone and intravenous immunoglobulin with no success. Unable to transfuse, she was treated with Chlorambucil $6 \mathrm{mg}$ for 10 days in 28 day cycles with prednisolone to which she responded well with no evidence of bone marrow suppression [2]. Her anaemia improved and the splenic size reduced. One year later she had another episode of haemolysis with strongly positive DAT which responded well to 4 doses of Rituximab $\left(375 \mathrm{mg} / \mathrm{m}^{3}\right)$. She maintained a good response for nearly 2 years following which she was seen at the clinic with abdominal distension and episodic pain. The ultrasound scan revealed a renal mass on the left side. The CT scan showed a renal mass with enlarged para-aortic lymph nodes which made lymphoma the most likely diagnosis. Patient refused any type of diagnostic or therapeutic intervention and it was decided to go for symptomatic management.

\section{Discussion}

Autoimmune haemolytic anaemia is a known complication of patients with lymphoma [2]. The treatment of AIHA in non-Hodgkin lymphoma depends on the type of lymphoma. Generally, AIHA of patients with non-Hodgkin lymphoma has a poor response to steroids [3]. There are many treatment options for these patients such as radiation therapy, chemotherapy, targeted therapy (therapy with monoclonal antibodies and proteasome inhibitors), biologic therapy (interferon), watchful waiting, new types of treatment like vaccine therapy and high-dose chemotherapy with stem cell transplant. Managing a patient with AIHA and lymphoma becomes a challenge when the patient refuses blood transfusions. The bleeding from thrombocytopenia and profound anaemia following high dose chemotherapy can be life threatening when the patient is unwilling to accept red blood cells or platelet transfusions due to religious convictions [4] (Figure 1).

Our patient was managed with low dose chemotherapy and rituximab during acute heamolytic episodes [3,5-7]. Blood products were not given. Patient went into remission and haemoglobin was

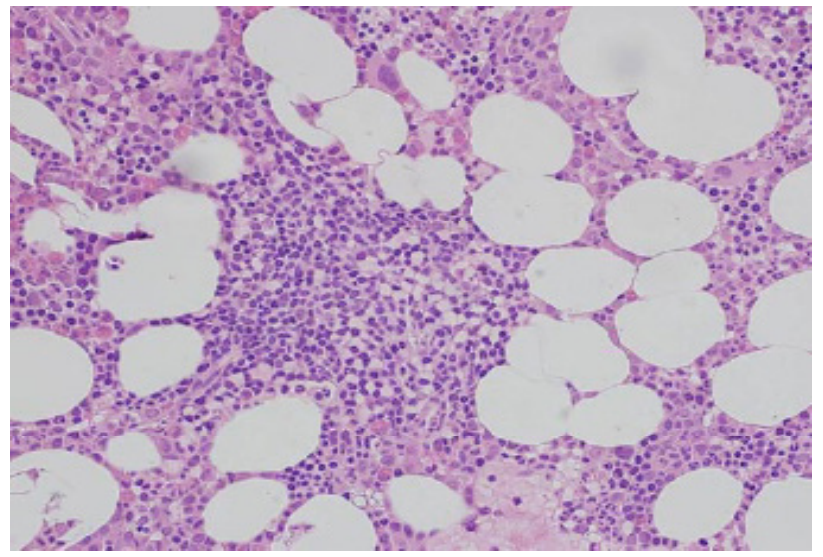

Figure 1: Trephine biopsy ( $\mathrm{H}$ and $\mathrm{E} \times 40)$ showing diffuse infiltration of lymphoid cells.

*Corresponding author: Gunawardena D, Department of Pathology, Faculty of Medical Sciences, University of Sri Jayewardenepura, India, Tel: 94112758718 ; E-mail: dammika.g@hotmail.com

Received November 01, 2018; Accepted November 20, 2018; Published November 26, 2018

Citation: Gunawardena D, Moonesinghe CS, Wijesiriwardena IS, Kulathilake HWCK (2018) Case Report of Autoimmune Haemolysis with Lymphoma-Managing the Impossible. J Blood Lymph S1: 002. doi: 10.4172/2165-7831.S1-002

Copyright: (c) 2018 Gunawardena D, et al. This is an open-access article distributed under the terms of the Creative Commons Attribution License, which permits unrestricted use, distribution, and reproduction in any medium, provided the original author and source are credited. 
Citation: Gunawardena D, Moonesinghe CS, Wijesiriwardena IS, Kulathilake HWCK (2018) Case Report of Autoimmune Haemolysis with LymphomaManaging the Impossible. J Blood Lymph S1: 002. doi: 10.4172/2165-7831.S1-002

maintained between 11-12 g/dL. Patient performed very well until she developed abdominal distension and a renal mass which was most likely to be a secondary deposit of lymphoma in the kidney.

\section{Conclusion}

This case highlights the possibility of managing a difficult patient out of protocol, to suit the current medical issues of the patient. Making rational decisions judicially at the correct time can improve the longevity and quality of life of an otherwise impossible situation.

\section{References}

1. Go RS, Winters JL, Kay NE (2017) How I treat autoimmune hemolytic anemia. Blood 129: 2971-2979.
2. Sallah S, Sigounas G, Vos P, Wan JY, Nguyen NP (2001) Autoimmune hemolytic anemia in patients with non-Hodgkin's lymphoma: characteristics and significance. Ann Oncol 11: 1571-1577.

3. Lechner K, Jäger U (2010) How I treat autoimmune hemolytic anemias in adults. Blood 116: 1831-1838.

4. Nev S, Swan V, Enger C (1998) Acute bleeding after bone marrow transplantation incidence and effect on survival. Blood 91: 469-477.

5. Hoffbrand AV, Catovsky D, Tudenham EGD (2010) Postgraduate Haematology Sixth edition.

6. Michel M (2011) Classification and Therapeutic Approaches in AlHA: An Update. Expert Rev Hematol 4: 607-618.

7. Valent $P$, Lechner $K$ (2008) Diagnosis and treatment of autoimmune haemolytic anaemia in adults: A clinical review. Wien Klin Wochenschr 120: 136-151. 